\title{
10 health stories that mattered Apr. 21-25
}

- A British Columbia health care worker was fired for refusing to get the influenza vaccine or wear a mask. This was the first year the province required health workers to get vaccinated or wear masks; $80 \%$ received the vaccine, up $10 \%$ over last year.

- Alcohol consumption is linked to $2 \%-4 \%$ of new cancer cases in Ontario, according to a report by Cancer Care Ontario. That works out to 1000-3000 new cases of cancer a year. Drinking alcohol, the report states, increases the risks of many cancers, including oral, liver, esophageal, colorectal and breast.

- Saskatchewan received its first cyclotron - a \$25-million, 25-tonne machine that will produce medical isotopes for nuclear imaging though it won't be operational until 2015. Provincial and federal funding paid for the particle accelerator, which was constructed in British Columbia.

- Alberta has created an online organ and tissue donation registry. Registering online indicates "intent to donate" but "legal consent" requires that a user print the online form, sign and date it in the presence of a witness, and then have the witness sign and date the form.

- British Columbia medical marijuana producer Greenleaf Medicinals has recalled its "purple kush" batch after a Health Canada inspection found problems with the company's production practices. The nature of the problems and the possible negative effects on users were not disclosed.

- Nearly a third of adult Canadians have experienced some form of child abuse, which has a "robust association" with mental conditions, found a study published in CMAJ. Conditions associated with child abuse include attention deficit disorder, suicidal ideation and suicide attempts.

- Government funding for refugee mental health services in British Columbia has been cut by almost $60 \%$, reducing the annual budget from $\$ 616000$ to $\$ 260000$. Only three full-time workers remain to provide the services to an immigrant population that welcomes an estimated 2000 newcomers each year.

- Nova Scotia will invest \$4.2 million to reduce wait times for orthopedic surgery, with about $\$ 1.2$ million dedicated to hiring a surgeon who specializes in foot and ankle surgeries. The province currently has only one surgeon who specializes in these procedures, and wait times for consults can be as long as 10 years.

- Physicians in Winnipeg, Manitoba, are pressuring the provincial government to ban artificial tanning for youths under the age of 18 because of concerns that the practice increases the risk of melanoma. Bans already exist in many provinces, including British Columbia, Ontario, Quebec and Nova Scotia.

- Provincial liquor boards in Canada seem skeptical about a powdered alcohol product called Palcohol that was recently approved, then not approved, for sale in the United States. The Liquor Control Board of Ontario said it wouldn't consider selling the product because of concerns including underage drinking and improper mixing with water that could result in rapid intoxication and alcohol poisoning. The Nova Scotia Liquor Corporation said "significant investigation and research" would be required before it would consider selling it. Roger Collier, CMAJ

CMAJ 2014. DOI:10.1503/cmaj.109-4789 